\title{
Assessment of neuroinflammation in a mouse model of obesity and $\beta$-amyloidosis using PET
}

Anna M. Barron ${ }^{1,3}$, Masaki Tokunaga ${ }^{1}$, Ming-Rong Zhang ${ }^{2}$, Bin $\mathrm{Ji}^{1}$, Tetsuya Suhara ${ }^{1}$ and Makoto Higuchi ${ }^{{ }^{*}}$

\begin{abstract}
Background: Obesity has been identified as a risk factor for cognitive decline and Alzheimer's disease (AD). The aim of this study was to investigate the effect of obesity on neuroinflammation and cerebral glucose metabolism using PET in a mouse model of $\beta$-amyloidosis and determine the relationship between these PET imaging biomarkers, pathogenic changes, and functional outcomes.

Methods: Three-month-old C57BL/J6 mice were fed either a standard (control group) or high-fat diet (obese group) for 3 months and intracerebroventricularly infused with vehicle or human beta amyloid 1-42 $\left(A \beta_{42}\right)$. We assessed obesity-induced abnormalities in peripheral metabolic indices including adiposity, fasting glucose, and glucose tolerance. Brain glucose metabolism was assessed by ${ }^{18} \mathrm{~F}-\mathrm{FDG}$ PET, and glial activation was assessed using the translocator protein (TSPO) ligand ${ }^{11} \mathrm{C}$-PBR-28. TSPO expression was confirmed by immunohistochemistry of brain sections obtained from scanned mice. The association between inflammatory state and ${ }^{11} \mathrm{C}$-PBR-28 PET signals was characterized by examination of the cytokine expression profile in both the serum and hippocampus by antibody array. Learning and memory performance was assessed in the object recognition task, and anxiety-related behavior was assessed in the elevated plus maze.
\end{abstract}

Results: Obesity combined with $A \beta$ infusion promoted neuroinflammation and cerebral hypermetabolism, and these signals were significant predictors of learning and memory performance in the object recognition task. In vivo TSPO signals were associated with inflammatory markers including CXCL1, CXCL2, CXCL12, CCL3, CCL5, TIMP-1, G-CSF, sICAM-1, and IL-1ra.

Conclusions: In vivo cerebral metabolism and TSPO signals indicate that obesity can accelerate amyloid-induced inflammation and associated cognitive decline.

Keywords: Beta amyloid, Translocator protein, Neuroinflammation, Cerebral metabolism, Alzheimer's disease

Abbreviations: A $\beta$, Beta amyloid; AD, Alzheimer's disease; AIC, Akaike information criterion; ANOVA, Analysis of Variance; $\mathrm{C5a}$, Complement component 5; $\mathrm{CCL}$, Chemokine ( $\mathrm{C}-\mathrm{C}$ motif) ligand; $\mathrm{CXCL}$, Chemokine ( $\mathrm{C}-\mathrm{X}-\mathrm{C}$ motif) ligand; EPM, Elevated plus maze; FDG, Fluoro-2-deoxy-D-glucose; G-CSF, Granulocyte colony-stimulating factor; GFAP, Glial fibrillary acidic protein; GM-CSF, Granulocyte macrophage colony-stimulating factor; HDL, High-density lipoprotein; IBA-1, lonized calcium-binding adaptor molecule 1; ICAM-1, Intracellular adhesion molecule 1; IFNY, Interferon gamma; IL, Interleukin; M-CSF, Macrophage colony-stimulating factor; MCI, Mild cognitive impairment; MRI, Magnetic resonance imaging; PBS, Phosphate-buffered saline; PET, Positron emission tomography;

(Continued on next page)

\footnotetext{
* Correspondence: higuchi.makoto@qst.go.jp

${ }^{1}$ Department of Functional Brain Imaging Research, National Institutes for

Quantum and Radiological Science and Technology, 4-9-1 Anagawa,

Inage-ku, Chiba-shi, Chiba 263-8555, Japan

Full list of author information is available at the end of the article
} 
(Continued from previous page)

SEM, Standard error of mean; SUV, Standardized uptake value; TIMP-1, Tissue inhibitor of metalloproteinase 1; TNF-

a, Tumor necrosis factor alpha; TSPO, Translocator protein; TREM-1, Triggering receptor expressed on myeloid cells

1 ; VOI, Volume of interest; \%ID/g, Percentage of injected dose per tissue volume

\section{Background}

Obesity is a global health issue owing to high intake of refined carbohydrates and saturated fat and increasingly sedentary lifestyles [1]. Growing evidence suggests that obesity at midlife increases the risk of cognitive decline and Alzheimer's disease (AD) in later life [2-4]. AD pathogenesis, which begins decades prior to the onset of symptoms $[5,6]$, is characterized by the accumulation of the toxic beta amyloid (A $\beta$ ) peptides, formation of neurofibrillary tangles, chronic inflammation, and neuronal loss $[5,7]$. Numerous imaging modalities including structural and functional magnetic resonance imaging (MRI) and positron emission tomography (PET) assessment of cerebral glucose metabolism and amyloid burden have proven diagnostically useful in mild cognitive impairment (MCI) and $\mathrm{AD}$ [8]. However, the relationship between imaging biomarkers and early midlife pathogenic changes leading to $\mathrm{AD}$, such as obesity, has remained elusive. Since obesity-driven inflammation and metabolic impairment have been identified as important mechanisms accelerating $\mathrm{AD}$ pathogenesis and functional impairment [9-13], they may represent potential early-stage imaging markers of cognitive decline and $\mathrm{AD}$ risk.

Neuroinflammation has been identified as a contributor to both the initiation and progression of $A D$. Accumulation of soluble $A \beta$ is suggested to induce inflammatory processes in $\mathrm{AD}$, activating glial cells and potentiating the production of proinflammatory cytokines [14]. In obesity, chronic systemic inflammation triggers neuroinflammation, thereby exacerbating $\mathrm{A} \beta$-induced degenerative cascades and $\mathrm{AD}$ progression [15]. The mitochondrial translocator protein (TSPO) is markedly upregulated in activated glia in inflammatory disease including $\mathrm{AD}$, believed to play a critical role in mediating glial responses to $\mathrm{AD}$ pathogenesis. In vitro studies using transgenic mouse models of $\mathrm{AD}$ indicated that TSPO expression is linked with neuronal toxicity and death [16, 17]. ${ }^{11}$ C-PBR-28 is a second-generation TSPO ligand with high affinity and penetration of the blood-brain barrier compared to the prototypic firstgeneration TSPO ligand, ${ }^{11}$ C-PK-11195 [18]. Previous studies have demonstrated the usefulness of ${ }^{11} \mathrm{C}$-PBR28 in subjects with AD [19] and multiple sclerosis [20] and in animal models of aging [21] and cerebral ischemia [22]. However, the detection of early-stage inflammatory changes associated with obesity-related cognitive decline and $\mathrm{AD}$ risk has not been investigated using TSPO ligands.
Cerebral glucose metabolism measured by ${ }^{18} \mathrm{~F}$-fluoro2-deoxy-D-glucose-PET (FDG PET) is widely used in AD as an index of neuronal loss [23]. Although cerebral metabolic changes prior to the development of neuronal loss in AD remains poorly understood, emerging evidence suggests that hypometabolism may be preceded by a hypermetabolic phase [24-27]. It is unclear if this early hypermetabolic stage reflects neuronal hyperactivity or inflammatory changes or if the hyperactivity is a cause (e.g., activity-driven $A \beta$ deposition) or result of $\mathrm{AD}$ pathogenesis (e.g., $\mathrm{A} \beta$-induced seizure activity or inflammation) [26, 27]. Transgenic mouse models of amyloidosis which do not develop neuronal loss may be useful tools for investigating metabolic changes associated early stages of $\mathrm{A} \beta$ pathogenesis [28-31]. However, use of ${ }^{18} \mathrm{~F}$-FDG PET in transgenic animal models may be hampered by the overexpression of amyloid precursor protein (APP) and non-A $\beta$ fragments of APP, which are known to modify synaptic and metabolic activity [28-31]. To circumvent this, here, we have used $A \beta$-infusion to investigate interactions between $A \beta$ - and obesity-driven inflammatory and metabolic abnormalities in vivo using ${ }^{11}$ C-PBR-28 and ${ }^{18}$ F-FDG PET, respectively, and determine the relationship between these imaging biomarkers, underlying pathogenic changes and functional outcomes.

\section{Methods}

\section{Animals and treatments}

Three-month-old male C57Bl/J mice were purchased (Clear, Japan) and maintained at the National Institute of Radiological Sciences vivarium facilities with food and water available ad libitum. Beginning at 3 months of age, mice were randomly assigned to groups ( $n=6 /$ group) and maintained on a standard diet $(10 \% \mathrm{kCal}$ fat; Research Diets D12450B Harlan Teklad, Indianapolis, IN) or a high-calorie, high-fat diet $(60 \% \mathrm{kCal}$ fat; Research Diets D12492, Harlan Teklad) for a period of 3 months. Body weights were monitored weekly, and fasting blood glucose was monitored fortnightly.

After 1 month of feeding, mice were anesthetized with isoflurane ( $3 \% v / v$ for induction, $1.5 \% v / v$ for maintenance), positioned in a stereotaxic apparatus and $0.9 \% \mathrm{sa}-$ line applied to the eyes. The scalp was shaved and cut, the skull exposed, and adhering tissue was removed with acetone. A cannula (Brain Infusion Kit 3, Alzet) was implanted in the left ventricle at the following coordinates: +1.0 medial/lateral, -0.3 anterior/posterior, -2.5 dorsal/ventral. The cannula was fixed to the skull 
using dental cement and connected to a mini-osmotic pump (Model 1002, Alzet) that was filled with either vehicle $(250 \mu \mathrm{g} / \mathrm{mL}$ high-density lipoprotein (HDL) in 4 mM HEPES with $2.5 \%$ DMSO) or $120-\mu \mathrm{M}$ oligomeric $A \beta-42$ [32]. Oligomeric $A \beta-42$ was prepared by solubilizing synthetic human $A \beta-42$ (Peptide Institute) to $1 \mathrm{mM}$ in hexafluoroisopropanol, then drying under vacuum in a SpeedVac. The peptide film was then resuspended in DMSO to $5 \mathrm{mM}$ and diluted in $4 \mathrm{mM}$ HEPES containing $250 \mu \mathrm{g} / \mathrm{mL}$ HDL (Millipore) to a final concentration of $120 \mu \mathrm{M}$. Pumps were partially coated with paraffin to adjust the infusion rate to $3 \mu \mathrm{L} /$ day for 1 month, then the filled pumps were incubated in sterile phosphate-buffered saline (PBS) at $37{ }^{\circ} \mathrm{C}$ for $40 \mathrm{~h}$ prior to implantation under the dorsal skin on the back. The incision site on the scalp was closed with suture, and mice were administered buprenorphrine $(0.05 \mathrm{mg} / \mathrm{kg}$ i.p., Henry Schein Inc.) post-operatively for analgesia. One spontaneous death occurred in the 8 weeks post-surgery treatment duration (obese $+\mathrm{A} \beta$ group).

All experimentation was carried out in strict accordance with the recommendations in the Guide for the Care and Use of Laboratory Animals of the National Institutes of Health and was approved by the Institutional Animal Care and Use Committee of the National Institutes for Quantum and Radiological Science and Technology, Japan.

\section{Glucose measurements}

Fasting blood glucose was assessed using a Nipro Freestyle Glucometer (Nipro Diagnostics, Florida, USA) from the whole blood collected via the tail vein while the mouse was under isofluorane general anesthesia. Mice were fasted overnight for $16 \mathrm{~h}$ prior to sample collection. Mice were fasted at baseline (time 0), 1, 2 months and sacrificed for assessment of blood glucose levels. Mice were additionally fasted overnight at 2.5 months for the ${ }^{18}$ F-FDG PET scans and again for 2 days later for the glucose tolerance test. For the glucose tolerance test, baseline glucose levels were measured, then fasted mice were injected with $2 \mathrm{mg}$ glucose/g body weight (i.p.), and blood glucose was measured from the whole blood collected via the tail vein 30,60 , and $120 \mathrm{~min}$ after injection.

\section{In vivo PET imaging}

TSPO signals were assessed by PET using ${ }^{11} \mathrm{C}-\mathrm{PBR}-28$, which was prepared according to previously published methods [33]. The specific activity of the end product was $80.7 \pm 14.7 \mathrm{GBq} / \mu \mathrm{mol}$ and the radiochemical purity exceeded $95 \% .{ }^{18}$ F-FDG was purchased from Nihon Medi-Physics Co. LTD (Tokyo, Japan). Mice were fasted prior to ${ }^{18}$ F-FDG PET scans, and blood glucose levels were assessed at the completion of scan.

Mice were anesthetized with $1.5 \%(v / v)$ isoflurane and administered ${ }^{11} \mathrm{C}$-PBR-28 $(27.9 \pm 0.9 \mathrm{MBq})$ or ${ }^{18} \mathrm{~F}$-FDG $(17.6 \pm 0.2 \mathrm{MBq})$ via a tail vein catheter while in a microPET Focus 220 animal scanner (Siemens Medical Solutions). Simultaneous with radioligand injection, 3D list mode data acquisitions were started and lasted $60 \mathrm{~min}$. Summation images were reconstructed with maximum a posteriori reconstruction (40-60 $\mathrm{min}$ for ${ }^{11} \mathrm{C}-\mathrm{PBR}-28$ and $20-60$ min for ${ }^{18} \mathrm{~F}$-FDG), and dynamic images were reconstructed with filtered back-projection using a 0.5$\mathrm{mm}$ Hanning filter, which were used for quantification of standardized uptake values (SUVs) and percentage of injected dose per tissue volume $(\% \mathrm{ID} / \mathrm{g})$. Volumes of interest (VOIs) were placed at the infusion site and in the hippocampal and cerebellar regions with reference to the MRI template (Fig. 1). Then, dynamic PET images were merged to the MRI template, and the tracer uptake in each VOI was estimated as $\% \mathrm{ID} / \mathrm{g}$ for ${ }^{11} \mathrm{C}$-PBR-28 (40-60 min) and SUV for ${ }^{18}$ F-FDG (20-60 min). PET image analysis described above was performed with PMOD image analysis software (version 3.4; PMOD Technologies, Inc., Zurich, Switzerland).

\section{Behavioral assessment}

Short-term working memory was assessed in the object recognition task. Mice were placed in the centre of an open field $(50 \times 50 \times 50 \mathrm{~cm})$ and allowed to freely explore for $3 \mathrm{~min}$ (habituation trial). Following a 2-h inter$\mathrm{val}$, mice were again placed in the centre of the maze between two identical objects and allowed to explore freely for 6 min (training trial). The frequency of the left and right object explorations were scored to test for spatial bias. After a 24-h inter-trial interval, one object was replaced with a novel object and the mouse was allowed to freely explore for $10 \mathrm{~min}$ (probe trial). The

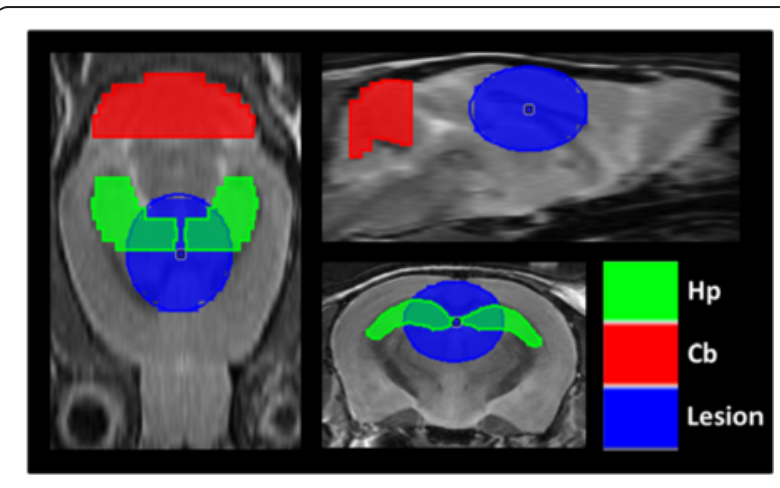

Fig. 1 Anatomical localization of volumes of interest (VOIs). Horizontal, sagittal, and coronal MRI slices of the mouse brain indicating the hippocampal ( $\mathrm{Hp})$, cerebellar (Cb), and lesion-site (Lesion) VOls used for PET quantification 
duration of novel $\left(D_{\mathrm{n}}\right)$ and familiar $\left(D_{\mathrm{f}}\right)$ object explorations were recorded and used to calculate the percent recognition $\left(D_{\mathrm{n}} /\left(D_{\mathrm{n}}+D_{\mathrm{f}}\right)\right)$.

Anxiety-related behavior was assessed in the elevated plus maze (EPM). Mice were placed in the center of a plus-shaped maze $(25 \mathrm{~cm} \times 8 \mathrm{~cm})$ with two open arms and two closed arms elevated $60 \mathrm{~cm}$ from the ground. The closed arms were surrounded by $24-\mathrm{cm}$ walls. Behavior was recorded in a 5-min period via overhead digital video and analyzed using SMART Automated Recording (Panlab). The total duration spent in the open arm was calculated as an index of anxiety-related behavior.

\section{Tissue collection and preparation}

Mice were fasted for $16 \mathrm{~h}$ prior to sacrifice then deeply anesthetized $(50 \mathrm{mg}$ sodium pentobarbital $/ \mathrm{kg}$ body weight, i.p.). Blood was collected via cardiac puncture and fasting blood glucose assessed. Serum was collected from the remaining blood and stored at $-80{ }^{\circ} \mathrm{C}$. Mice were then intracardially perfused with ice-cold, sterile saline, and one hemibrain was submersion fixed in $4 \%$ paraformaldehyde/0.1 M PBS ( $\mathrm{pH} 7.4$ ) for $24 \mathrm{~h}$ for immunohistochemistry. The hippocampus was rapidly dissected from the remaining hemibrain and snap frozen on liquid nitrogen. Retroperitoneal and subcutaneous fat pads were collected at necropsy and weighed as an indicator of visceral adiposity and body composition.

\section{Immunohistochemistry}

Fixed hemibrains were cryoprotected in $30 \%$ sucrose, frozen, and sectioned in the horizontal plane at $20 \mu \mathrm{M}$ using a cryostat. Sections were soaked in PBS for $5 \mathrm{~min}$, then immunolabeled with antibodies directed against TSPO (rabbit monoclonal, 1:1000; Abcam), glial fibrillary acidic protein (GFAP; rat monoclonal, 1:1000 dilution, 2.2B10, Zymed), or anti-ionized calcium-binding adaptor molecule-1 (IBA-1; rabbit polyclonal, 1:1000 dilution, WAKO). Non-specific staining was blocked in blocking reagent (PerkinElmer) for $1 \mathrm{~h}$ at room temperature, then immunolabeled overnight at $4{ }^{\circ} \mathrm{C}$ with primary antibodies. Sections were then washed three times in PBS for $5 \mathrm{~min}$ and then incubated with anti-rabbit or anti-rat IgG biotin (1:1000) for $1 \mathrm{~h}$ at room temperature. Immunoreactivity was visualized using tetramethylrhodaminelabeled tyramide signal amplification (PerkinElmer). Sections were mounted with VectaSheild (Vector Laboratories), and coverslips were sealed with enamel. Photomicrographs were captured with a fluorescence microscope/digital camera (BZ-X700, Keyence) at $\times 20$ magnification and then thresholded at a predetermined, constant value using NIH Image 1.61 to create a binary image identifying positive and negative immunolabeling and the intensity assessed.

\section{Cytokine antibody microarray}

Mouse cytokine antibody arrays (cytokine array panel A, Proteome Profiler, R\&D systems, Minneapolis, USA) were used to analyze cytokine expression profiles in serum and hippocampal samples according to the manufacturer's instructions. Frozen hippocampus samples were homogenized by bead cell disrupter (Micro Smash) in PBS containing complete ULTRA protease inhibitors (Roche). A digital imaging system (Chemidoc, Bio-Rad) was used to detect chemiluminescent signals which were analyzed using ImageJ software (NIH). Measured cytokines included the following: complement component 5 (C5a), chemokine (C-C motif) ligand 1 (CCL1), CCL2, CCL3, CCL4, CCL5, CCL-11, CCL12, CCL17, chemokine (C-X-C motif) ligand 1 (CXCL1), CXCL2, CXCL9, CXCL10, CXCL11, CXCL12, CXCL13, granulocyte colony-stimulating factor (G-CSF), granulocyte macrophage colony-stimulating factor (GM-CSF), intracellular adhesion molecule 1 (ICAM-1), interferon gamma (IFN$\gamma)$, interleukin-1 $\alpha$ (IL-1 $\alpha)$, IL-1 $\beta$, IL-1ra, IL-2, IL-3, IL-4, IL-5, IL-6, IL-7, IL-10, IL-12p70, IL-13, IL-16, IL-17, IL23, IL-27, macrophage colony-stimulating factor (MCSF), tissue inhibitor of metalloproteinase 1 (TIMP-1), tumor necrosis factor alpha (TNF- $\alpha$ ), and triggering receptor expressed on myeloid cells 1 (TREM-1).

\section{Statistical analysis}

Parametric data was analyzed by one-way analysis of variance (ANOVA) or linear mixed model analysis using the Statistical Package for Social Sciences (SPSS: version 11.5; SPSS Inc., IL, USA). Data were analyzed using the information-theoretic approach, using the Akaike information criterion (AIC) model selection process and linear regression with Bonferroni adjustment for multiple analyses. All data are presented as mean \pm standard error of the mean (SEM). Significance was set at a threshold of $p<0.05$.

\section{Results}

In this study, we investigated obesity-driven inflammatory and metabolic abnormalities in an $A \beta$-infusion model of $\beta$-amyloidosis using PET. Obesity and hyperglycemia were evident in the high-fat fed mice after 1 month of feeding, accompanied by significantly increased abdominal and subcutaneous fat deposition and impaired glucose tolerance at sacrifice (Fig. 2b-d). Mice were infused with either vehicle or oligomeric human $A \beta_{42} 1$ month after feeding initiation, once obesity was already evident in high-fat fed groups (Fig. 2a). In vivo TSPO signals were assessed at baseline, 2, and 3 months after feeding initiation via ${ }^{11} \mathrm{C}-\mathrm{PBR}-28 \mathrm{PET}$, while cerebral metabolism was assessed 2.5 months after feeding initiation via ${ }^{18}$ F-FDG PET (Fig. 2a). Learning and memory and anxiety-related behaviors were assessed 3 months 
a

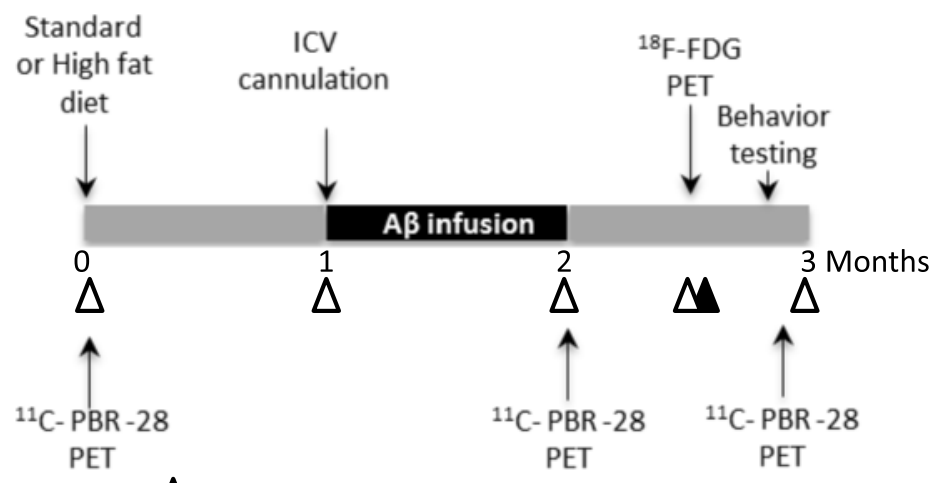

$\triangle$ Fastening for measurement of blood glucose levels

$\triangle$ Fastening for glucose tolerance test

b

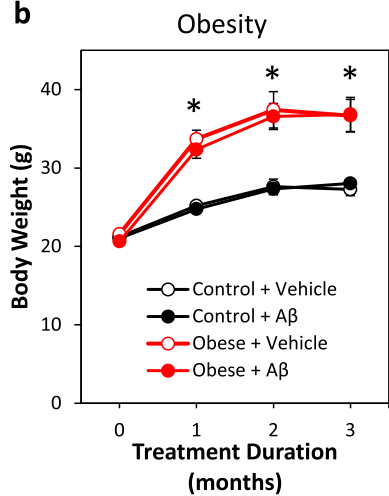

d

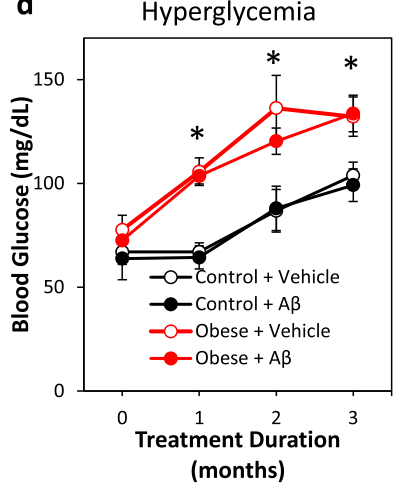

C

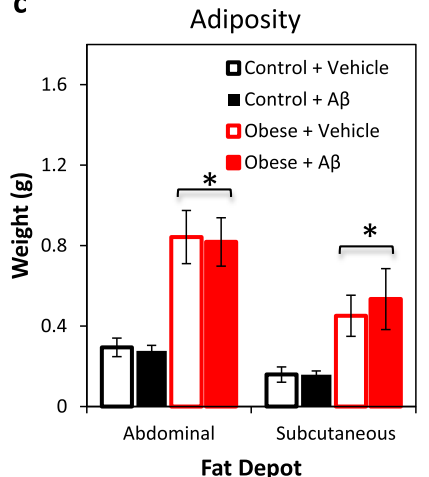

e

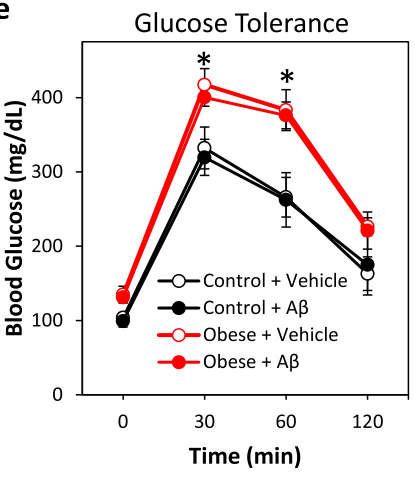

Fig. 2 Treatment schedule and validation of the obesity model. a Feeding with regular (control group) or high-fat diet (obese groups) began at month 0 , at which time baseline TSPO signals were also assessed in vivo via ${ }^{11} \mathrm{C}$-PBR-28 PET. ICV cannulas for infusion of vehicle or A 3 were implanted at month 1 and infusion was continuous until month 2. ${ }^{11} \mathrm{C}$-PBR-28 PET was repeated at months 2 and $3 .{ }^{18} \mathrm{~F}$-FDG PET was assessed at month 2.5. Behavior testing was carried out at month 3, prior to the final ${ }^{11} \mathrm{C}-\mathrm{PBR}-28$ PET scan. Fasting time points are indicated by arrowheads. Tissues were collected 3 months after the initiation of regular or high-fat diet feeding. $\mathbf{b}$ Body weight in mice across the 3-month treatment duration, with significant obesity observed in high-fat fed groups from 1 month. Month $0: F=-11.59, p=0.38$; month 1: $F=11.05, p<0.001$; month 2: $F=10.46, p=0.001$; month 3: $F=9.98, p=0.003$. c Abdominal retroperitoneal fat pad and subcutaneous fat pad weight in mice, confirming increased adiposity in high-fat fed groups. $F=9.21, p=0.01$. d Fasting blood glucose across the 3-month treatment duration, with significant hyperglycemia observed in high-fat fed groups from 1 month. Month $0: F=0.65, p=0.59$; month $1: F=19.89, p<0.001 ;$ month $2: F=5.69, p=0.006$; month 3: $F=4.93, p=0.01$. e Glucose tolerance test in control and obese mice infused with vehicle or $A \beta$. Obese mice exhibited significant glucose intolerance. Baseline: $F=4.99, p=0.01 ; 30$-min post-glucose challenge: $F=4.74, p=0.01 ; 60$-min post-glucose challenge: $F=5.67, p=0.006$. Data presented as mean \pm SEM. ${ }^{*} p<0.05$ relative to matched time point control mice 
after feeding initiation, prior to the final ${ }^{11} \mathrm{C}-\mathrm{PBR}-28$ PET scan (Fig. 2a).

\section{Longitudinal in vivo PET imaging of obesity and A $\beta$-triggered inflammation using ${ }^{11} \mathrm{C}$-PBR-28}

To examine the effect of obesity and $\beta$-amyloidosis on TSPO inflammatory signals, ${ }^{11} \mathrm{C}-\mathrm{PBR}-28$ uptake was compared at baseline, 2-, and 3-month treatment time points (Fig. 3). Obesity can alter the whole body distribution of ${ }^{11} \mathrm{C}-\mathrm{PBR}-28$; therefore, the brain uptake expressed as $\% \mathrm{ID} / \mathrm{g}$ may result in an underestimation of TSPO signals in obese groups (Fig. 3a). A $\beta$ significantly increased ${ }^{11} \mathrm{C}$-PBR-28 signals at the infusion site and extending into the dorsal hippocampus in both control and obese groups at the 2-month treatment time point $(F=10.94 ; p=0.001$; Fig. 3b-e). At 3 months, increased ${ }^{11} \mathrm{C}$-PBR-28 signals persisted in obese but not in control mice infused with $\mathrm{A} \beta(F=3.80, p=0.03$; Fig. 3b, e).

In vivo hippocampal TSPO signals were confirmed in tissues by immunohistochemistry (Fig. 4). Significantly increased TSPO immunoreactivity was observed in the hippocampus of A $\beta$-infused obese mice $(F=4.51, p=$ 0.007; Fig. $4 \mathrm{~b})$, and TSPO immunoreactivity correlated with in vivo hippocampal ${ }^{11} \mathrm{C}$-PBR-28 signals $(R=0.74$, $P<0.001$; Fig. 4c).

\section{Obesity and $A \beta$ synergistically increase hippocampal gliosis} To assess whether ${ }^{11} \mathrm{C}$-PBR-28 PET signals at 3 months were associated with gliosis, IBA-1 and GFAP levels were assessed by immunohistochemistry in the hippocampus (Fig. 5a). Obesity combined with $A \beta$ infusion significantly increased IBA-1 immunoreactivity relative to vehicle-treated control mice $(F=2.96, p=0.05$; Fig. $5 b)$ and increased GFAP immunoreactivity compared to all other groups $(F=5.13, p=0.004$; Fig. $5 \mathrm{c})$. Hippocampal ${ }^{11}$ C-PBR-28 PET signals significantly correlated with hippocampal IBA-1 $(r=0.45, p=0.05$; Fig. $5 \mathrm{~d})$ and GFAP immunoreactivity $(r=0.62, p=0.005$; Fig. $5 \mathrm{e})$.

To characterize the association between inflammatory state and ${ }^{11} \mathrm{C}$-PBR-28 PET signals, the cytokine expression profile in both the serum and hippocampus was evaluated by an antibody array (Fig. 5f). Correlation and multiple regression analyses were conducted to examine the relationship between ${ }^{11} \mathrm{C}$-PBR-28 PET signals (\%ID/g) in the hippocampus measured at the final time point and potential inflammatory predictors (Table 1). Serum levels of M-CSF and IL-2 and hippocampal levels of CCL5, CCL3, IL-1ra, CCL2, CXCL9, and TIMP-1 significantly positively correlated with ${ }^{11} \mathrm{C}$-PBR-28 PET signals, while hippocampal CCL17 and IL-6 significantly negatively correlated. Hippocampal ${ }^{11} \mathrm{C}-\mathrm{PBR}-28$ PET signals were significantly predicted by both serum and hippocampal CXCL12 and CXCL13; serum IL-13, IL-1 $\beta$, CXCL1, CXCL2, CCL3, CCL5, and TIMP-1; and hippocampal G-
CSF, IL-1ra, IL-6, and ICAM-1 as assessed by multiple linear regression analysis, with the predictor variables explaining greater than $99 \%$ of ${ }^{11} \mathrm{C}$-PBR-28 PET signal variability $\left(F=8014.77, p<0.001, R^{2}=0.999\right.$; Table 1$)$.

\section{PET imaging of obesity and $A \beta$-induced effects on cerebral metabolism using ${ }^{18} \mathrm{~F}$-FDG PET}

To examine the effect of obesity and $\beta$-amyloidosis on cerebral metabolism, ${ }^{18}$ F-FDG uptake was examined at the 2.5-month treatment time point (Fig. 6). A significant increase in ${ }^{18}$ F-FDG uptake in the hippocampus but not the cerebellum was observed in $A \beta$-infused obese mice (hippocampus: $F=3.99 ; p=0.02$; cerebellum: $F=2.23, p=0.12$; Fig. 6). Hippocampal ${ }^{18}$ F-FDG SUVs were not significantly associated with markers of adiposity or glucose metabolism (data not shown).

\section{${ }^{11} \mathrm{C}-\mathrm{PBR}-28$ and ${ }^{18} \mathrm{~F}$-FDG PET signals predict learning and memory impairment}

At the 3-month treatment time point, the effect of obesity and $A \beta$ infusion on anxiety-related behavior and learning and memory performance was assessed in the EPM and the object recognition tasks, respectively. Obesity significantly increased in anxiety-related behavior, resulting in increased latency to enter the open arm compared to the control mice, while obesity combined with $A \beta$-infusion increased anxiety-related behavior compared to both vehicle and $\mathrm{A} \beta$-infused control groups $(F=11.54, p<0.001$; Fig. 7a). Treatment did not affect locomotor activity, with no significant effect of treatment on total distance moved in the EPM $(F=0.11, p=0.96)$. Although a significant effect of treatment was observed on object recognition performance $(F=10.32, p=0.02)$, no significant group differences were observed by post hoc analysis, with the effect of obesity combined with $A \beta$ infusion approaching significance ( $p=0.06$; Fig. 7b). Interestingly, ${ }^{18}$ F-FDG SUVs significantly correlated with anxiety-related behavior in the elevated plus maze $(r=0.48, p=0.02)$ and negatively correlated with learning and memory in the object recognition task $\left(r=-0.46, p=0.02\right.$; Fig. 7c). Hippocampal ${ }^{18}$ F-FDG and ${ }^{11} \mathrm{C}-\mathrm{PBR}-28$ PET signals at 3 months significantly predicted learning and memory performance but not anxiety-related behavior as assessed by multiple linear regression analysis, with the predictor variables explaining approximately $40 \%$ of the variability in object recognition performance $(F=6.06, p=0.009$, $\left.R^{2}=0.39\right)$. Both ${ }^{18}$ F-FDG $(B=-19.55, \quad \beta=-0.62, p=$ $0.005)$ and ${ }^{11}$ C-PBR-28 $(B=-17.59, \beta=-0.45, p=0.03)$ significantly contributed to the model.

\section{Discussion}

Using ${ }^{11} \mathrm{C}$-PBR-28-PET, we detected elevated TSPO associated with activated astrocytes and microglia resulting 


\section{a}

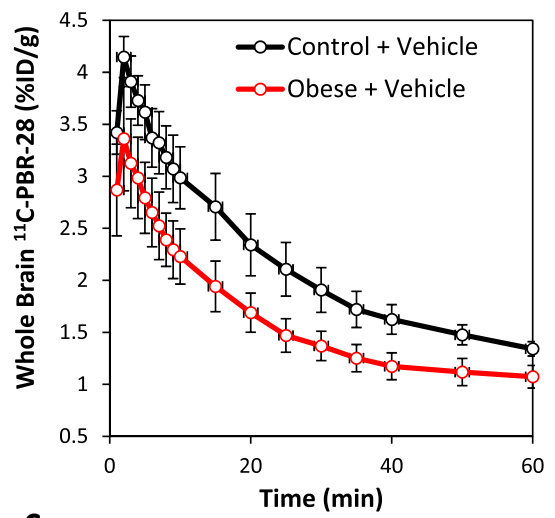

C

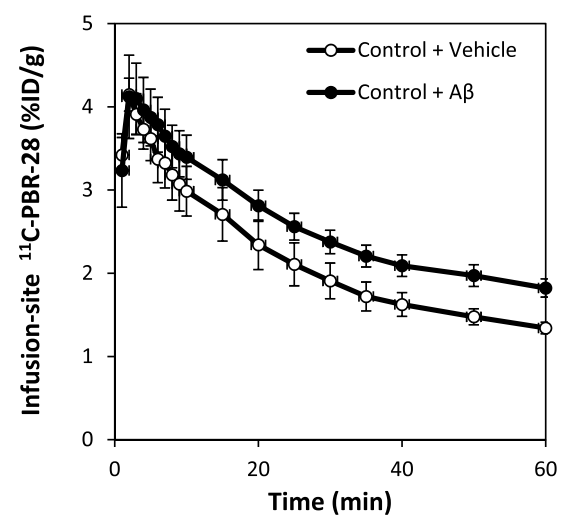

b
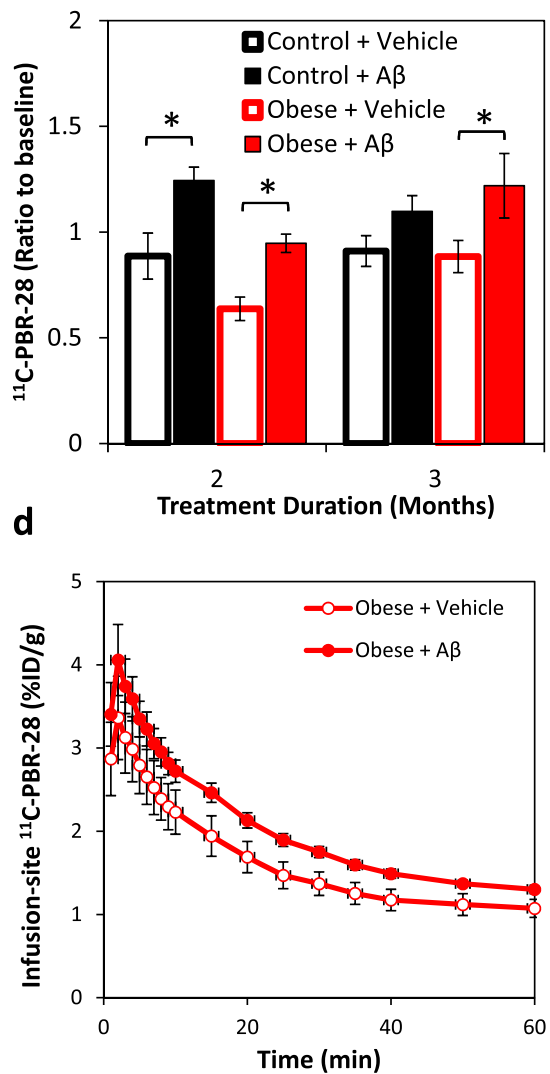

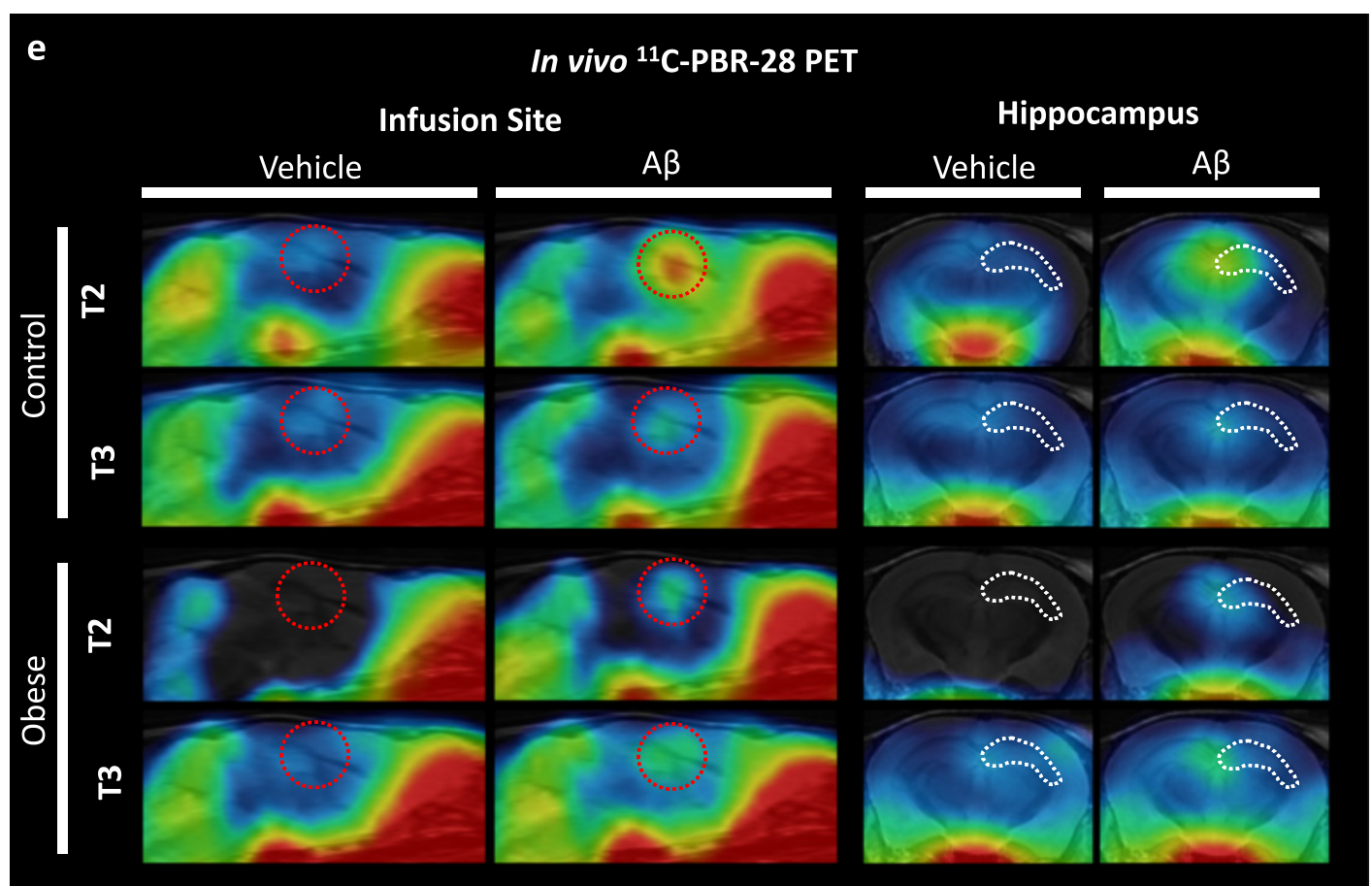

Fig. 3 (See legend on next page.) 
(See figure on previous page.)

Fig. $3 \mathrm{~A}$-triggered inflammatory signals detected by in vivo PET with ${ }^{11} \mathrm{C}$-PBR-28. a Whole-brain time activity curves in control versus obese mice 2 months post-treatment. Obesity significantly reduced brain ${ }^{11} \mathrm{C}-\mathrm{PBR}-28$ uptake, most likely reflecting altered whole body ${ }^{11} \mathrm{C}$-PBR-28 distribution. b Group comparison of ${ }^{11} \mathrm{C}-\mathrm{PBR}-28$ accumulation at the infusion site at 2 and 3 months post-treatment (relative to individual baseline accumulation). Obesity combined with $A \beta$ infusion synergistically increased radioligand accumulation at the infusion site, peaking at 2 months, but persisting at 3 months. c Time activity curves at the infusion site of vehicle versus A $\beta$-infused mice control mice at 2 months. $\mathbf{d}$ Time activity curves at the infusion site in vehicle versus A $\beta$-infused obese mice at 2 months. e Sagittal and coronal PET images in control and obese mice infused with vehicle or A 3 at 2 (T2) and 3 months post-treatment (T3). A marked increase in radioactivity was observed surrounding the $A \beta$ infusion site in the lateral ventricle (indicated by dashed red outline) extending into the dorsal hippocampus (indicated by white dashed outline). Images were generated by summation of dynamic data between 40 and 60 min after injection of ${ }^{11} \mathrm{C}$-PBR-28 and were overlaid on the MRI template. ${ }^{*} p<0.05$

from $A \beta$-induced inflammation. The $A \beta$-induced inflammatory response was transient, with TSPO signals no longer significantly elevated at the completion of the experiment. However, the magnitude and duration of the A $\beta$-induced inflammatory response was exacerbated by obesity, even though obesity alone did not increase TSPO inflammatory signals. Previous studies using TSPO as a marker of inflammation in transgenic mouse models of $\beta$-amyloidosis have also reported elevated TSPO signals detected by PET, although only in aged mice at late stages of neuropathology [17, 34, 35]. What remains unclear is to what extent TSPO expression represents deleterious versus trophic glial responses. While many studies have focused on TSPO as a marker of deleterious gliosis, reporting good correlations between microglial markers and TSPO PET signals [36], some evidence suggests that TSPO-positive glial activation may be associated with trophic glial functions including $\mathrm{A} \beta$ clearance [37]. To address this, in the current study, the systemic and hippocampal cytokine profile was examined to determine which specific inflammatory factors were associated with in vivo TSPO signals. Serum levels of numerous obesity-linked chemokines promoting adipocyte proliferation (TIMP-1 [38]) and adipose macrophage infiltration (CXCL1 [39, 40], CXCL2 [41], CXCL12 [42], CCL3 [43], and CCL5 [44]) were found to be significant predictors of in vivo hippocampal TSPO signals. Interestingly, in the hippocampus, levels of GCSF [45, 46], ICAM-1 [47], and CXCL12 [48] and IL-1ra [49], which have been identified as inflammatory factors

\section{a}

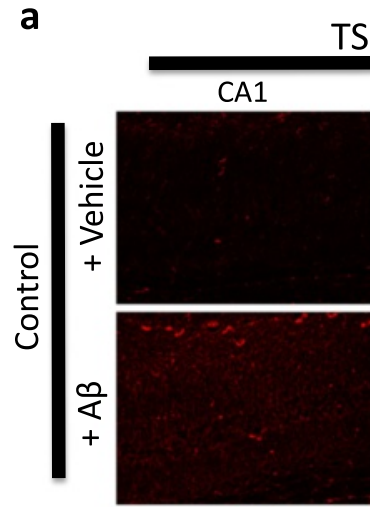

TSPO

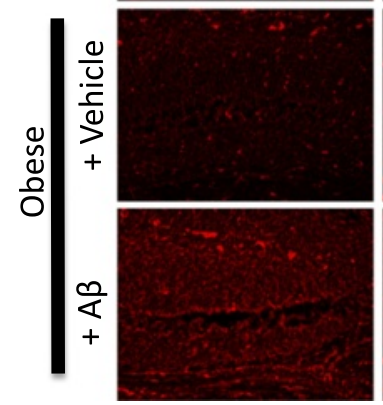

\section{Dentate Gyrus}
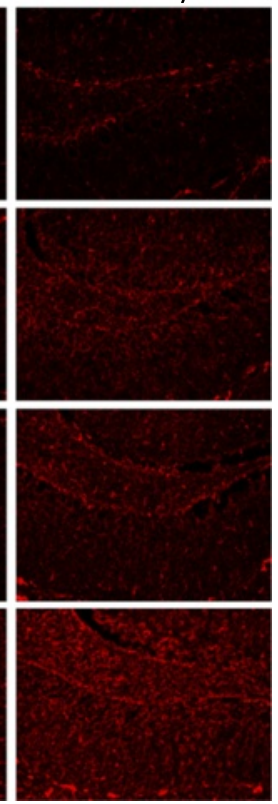

b

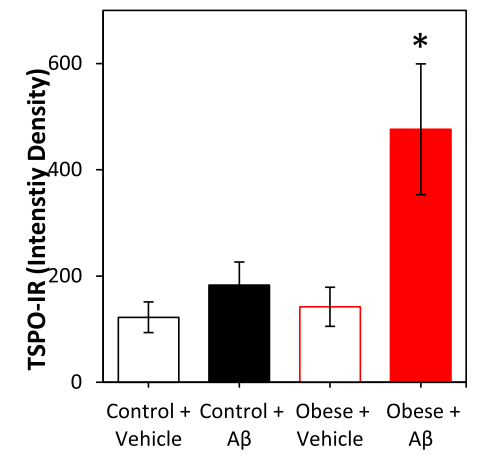

C

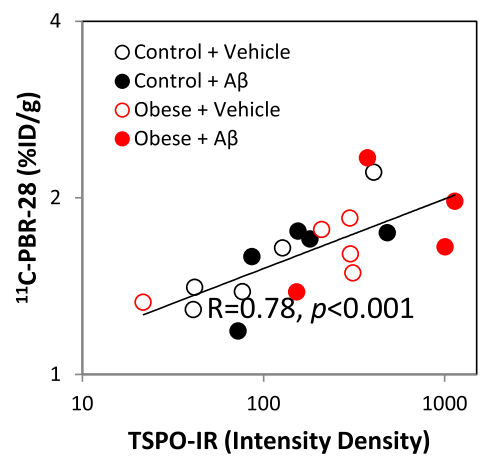

Fig. 4 Obesity and A increase hippocampal TSPO immunoreactivity. a Representative images of TSPO immunoreactivity (red) in the CA1 and dentate gyrus regions of the hippocampus. $\mathbf{b}$ Quantification of TSPO immunoreactivity (TSPO-IR) in the CA1 and dentate gyrus regions of control and obese mice infused with either vehicle or A . Obesity combined with $A \beta$ infusion significantly increased hippocampal TSPO immunoreactivity. c Association between hippocampal ${ }^{11} \mathrm{C}-$ PBR-28 accumulation at 3 months and TSPO immunoreactivity. Data presented as mean \pm SEM. $p<0.05$ 


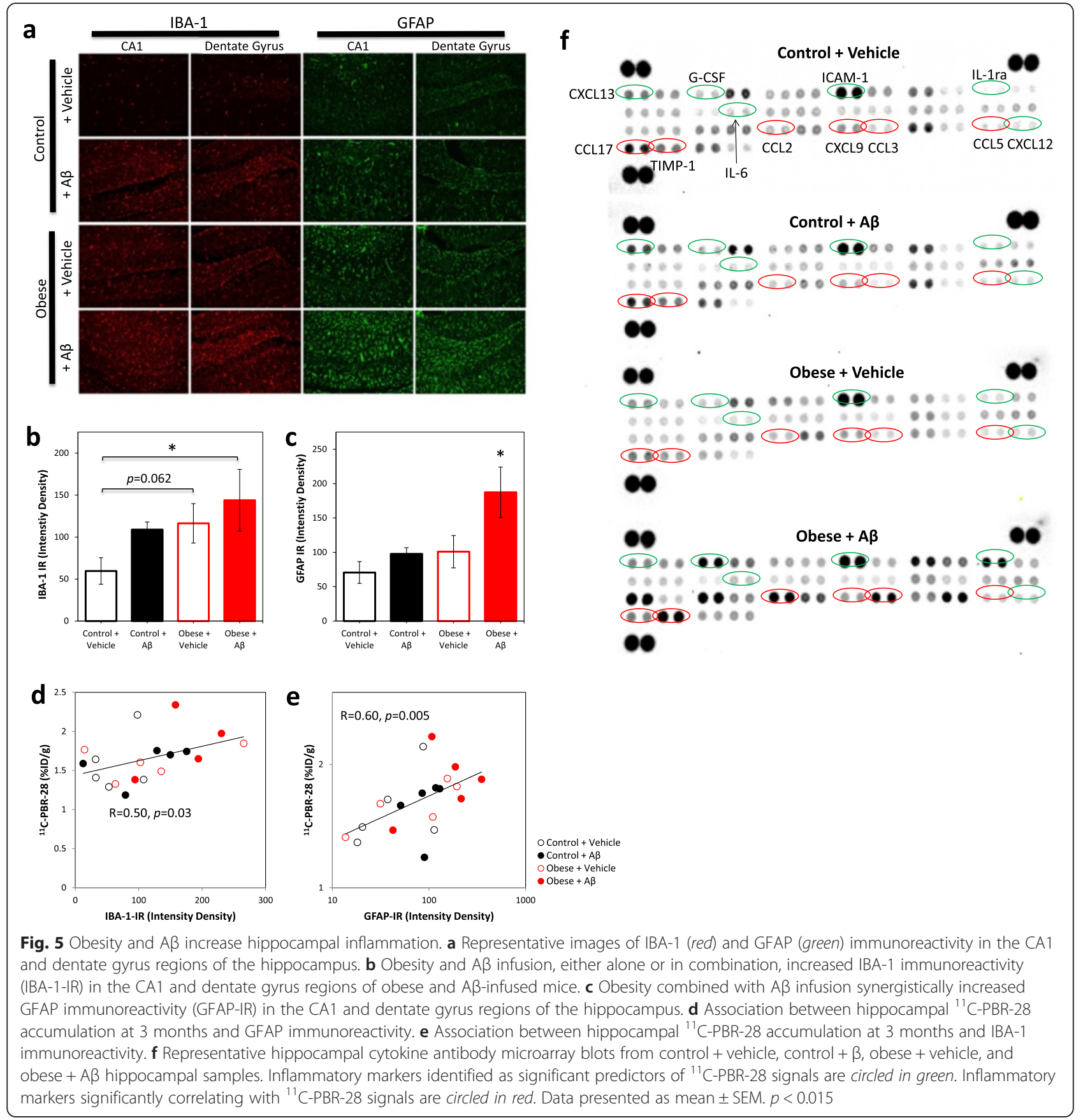

important in the regulation of amyloid clearance, significantly predicted in vivo hippocampal TSPO signals. Identification of the TPSO-associated inflammatory profile is necessary in order to understand the specific glial functions associated with TSPO signals, which is essential for the validation of TSPO as an effective biomarker of $\beta$-amyloidosis in AD.

In contrast to clinical observations in advanced $\mathrm{AD}$, in the current study, $\beta$-amyloidosis and cognitive impairment were associated with increased cerebral metabolism as assessed by ${ }^{18}$ F-FDG PET. Numerous other studies have also associated hypermetabolism with early stages of amyloid pathology in transgenic mouse models of $\beta$ amyloidosis [28-31]. Luo et al. reported hypermetabolism in young $\operatorname{Tg} 2576$ mice, prior to the development of plaques [29]. Previous studies have suggested hypermetabolism may result from increased gliosis in the absence of neuronal loss; however, we observed poor overlap between regions of hyperactivity and TSPO signals and no association between cerebral metabolism and markers of gliosis. Our findings suggest that hypermetabolic changes cannot be explained 
Table 1 Multivariate linear regression analysis of serum and hippocampal cytokines associated with in vivo hippocampal ${ }^{11} \mathrm{C}-\mathrm{PBR}-28$ uptake assessed by PET

\begin{tabular}{|c|c|c|c|c|c|}
\hline & & \multirow[t]{2}{*}{ Cytokine } & \multirow{2}{*}{$\begin{array}{l}{ }^{11} \text { C-PBR-28 } \\
\text { correlation }\end{array}$} & \multicolumn{2}{|c|}{ Multiple regression weights } \\
\hline & & & & $b$ & $\beta$ \\
\hline \multirow[t]{11}{*}{ Serum } & Predictors & TIMP-1 & 0.075 & $0.0011^{* *}$ & 2.3454 \\
\hline & & CXCL1 & -0.129 & $-0.0008^{* *}$ & -1.9194 \\
\hline & & CXCL2 & 0.25 & $0.0040^{* *}$ & 1.6419 \\
\hline & & CCL3 & -0.057 & $-0.0026^{* *}$ & -1.5286 \\
\hline & & CCL5 & 0.038 & $0.0023^{* *}$ & 0.8512 \\
\hline & & $\| L-1 \beta$ & 0.053 & $-0.0012^{* *}$ & -0.6740 \\
\hline & & $\mid \mathrm{L}-13$ & 0.281 & $0.0002^{* *}$ & 0.5435 \\
\hline & & CXCL12 & -0.099 & $0.0002^{* *}$ & 0.3181 \\
\hline & & CXCL13 & 0.137 & $-0.0003^{* *}$ & -0.2792 \\
\hline & Correlates & M-CSF & $0.650^{* *}$ & & \\
\hline & & IL-2 & $0.537^{*}$ & & \\
\hline \multirow[t]{12}{*}{ Hippocampus } & Predictors & CXCL13 & 0.045 & $-0.0024^{* *}$ & -2.923 \\
\hline & & G-CSF & 0.069 & $0.0074^{* *}$ & 2.159 \\
\hline & & IL-1ra & $0.641^{*}$ & $0.0072^{* *}$ & 1.550 \\
\hline & & IL-6 & $-0.531^{*}$ & $-0.0001^{* *}$ & -0.518 \\
\hline & & CXCL12 & 0.389 & $-0.0008^{* *}$ & -0.625 \\
\hline & & sICAM-1 & -0.245 & $-0.0008^{*}$ & -0.474 \\
\hline & Correlates & CCL17 & $-0.838^{* * *}$ & & \\
\hline & & CCL3 & $0.691^{* *}$ & & \\
\hline & & CCL2 & $0.637^{*}$ & & \\
\hline & & CXCL9 & $0.634^{*}$ & & \\
\hline & & TIMP-1 & $0.522^{*}$ & & \\
\hline & & CCL5 & $0.553^{*}$ & & \\
\hline
\end{tabular}

Abbreviations: $b$ unstandardized coefficients, $\beta$ standardized coefficients, TIMP-1 tissue inhibitor of metalloproteinases, M-CSF macrophage colony-stimulating factor IL-2 interleukin 2, G-CSF granulocyte colony-stimulating factor, IL-ra interleukin 1 receptor antagonist, IL-6 interleukin 6, ICAM-1 intracellular adhesion molecule 1 ${ }^{*} p<0.05 ;{ }^{* *} p<0.01$; ${ }^{* * *} p<0.001$

by gliosis alone. Multiple metabolic disturbances like altered glucose uptake and glycolytic metabolism has been mechanistically implicated in $\beta$-amyloidosis [50] and $A \beta$-induced astrocytic and neuronal hyperactivity and seizure activity [51-54]. In very young AD mutation carriers, approximately 25 years before the expected onset of symptoms, region-specific hypermetabolism is observed prior to the development of hypometabolism [24]. Likewise, amyloid deposition has been found to be associated with hypermetabolism in normal aging and MCI [25-27]. Functional MRI (fMRI) studies have also demonstrated increased brain activation in normal controls with amyloid deposition [55], in MCI [56-60] and in subjects at genetic risk for $\mathrm{AD}$ [61-63]. Cerebral hypermetabolism may be induced in early stages of $\beta$-amyloidosis, reflecting $A \beta$ induced pathogenic mechanisms including glial and neuronal hyperactivity, preceding neuronal loss.

In contrast to our previous findings [13], in the current study, obesity alone did not result in a significant deficit in learning and memory performance in the object recognition task. The lack of any deficit in obese mice in the current study is likely a consequence of poor performance of vehicle-treated control mice, which exhibited around $60 \%$ recognition. From our previous studies, we expect the performance of control mice to be around $75 \%$ in this task. We hypothesize that the reduced performance observed in control mice in the current study may be the consequence of repeated interventions including the pump and cannula implantation surgery and imaging experiments, with the stress on the procedures potentially impairing cognitive performance. This reduced the overall sensitivity of the object recognition test, making it difficult to detect impairment resulting from the experimental manipulations.

Interestingly, we did not observe any significant effect of obesity alone on markers of neuroinflammation, cerebral metabolism, or cognitive function. Findings from previous studies are mixed, with some studies reporting 

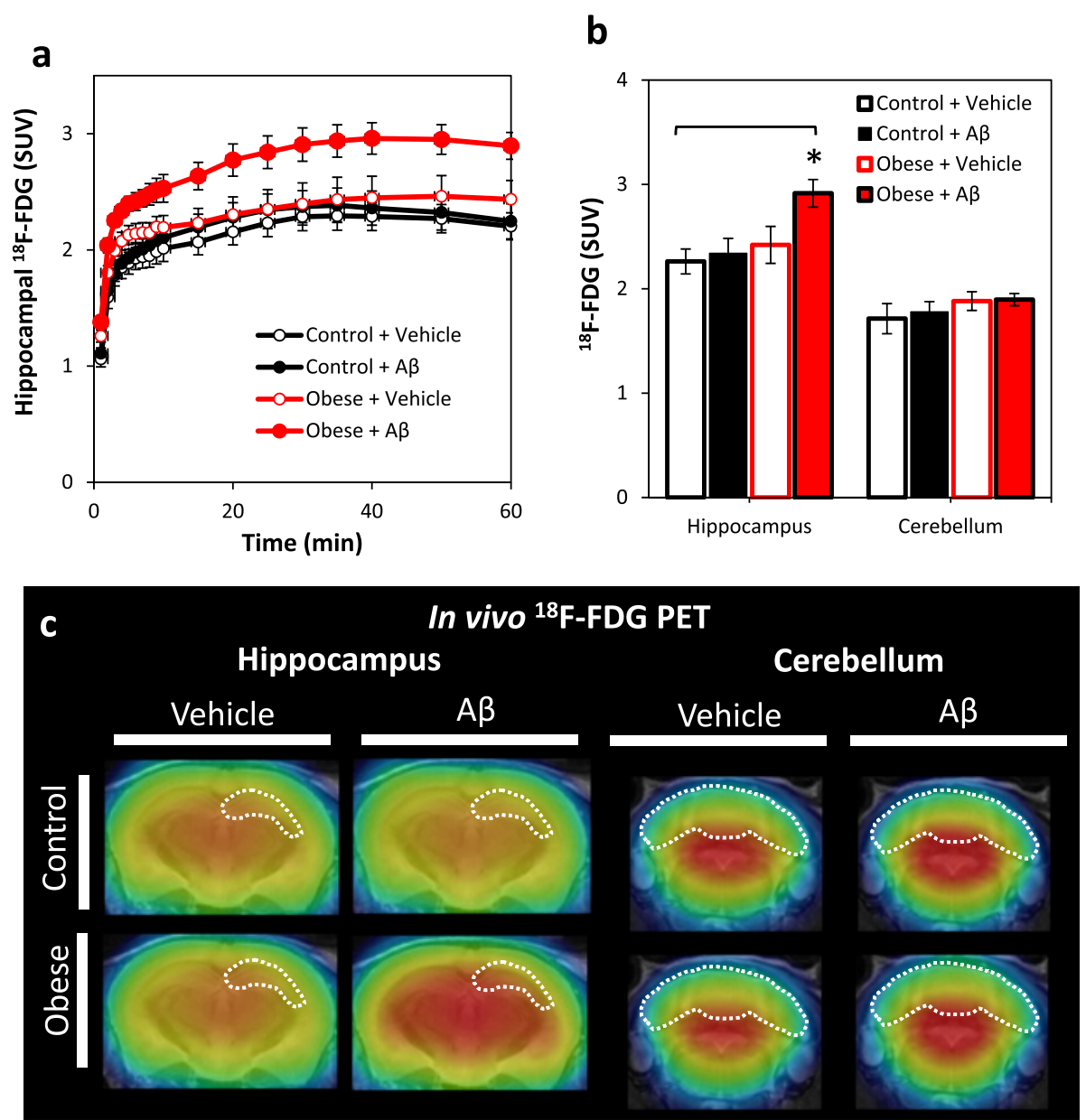

Fig. 6 Obesity and Aß-triggered hyperactive cerebral metabolism detected by in vivo PET with ${ }^{18} \mathrm{~F}$-FDG. a Hippocampal ${ }^{18} \mathrm{~F}$-FDG time activity curves in control versus obese mice. $\mathbf{b}$ Group comparison of cerebral metabolism assessed by ${ }^{18} \mathrm{~F}$-FDG accumulation in the hippocampus and cerebellum. Obesity combined with A infusion synergistically increased radioligand accumulation in the hippocampus but not in the cerebellum. c Representative coronal ${ }^{18}$ F-FDG PET images in vehicle or A $\beta$-infused control (top panel) and obese mice (bottom panel). A marked increase in radioactivity was observed in the hippocampus (indicated by dashed line, left panel) and underlying limbic structures. No effect of treatment was observed on radioactivity in the cerebellum (indicated by white dashed line, right panel). Images were generated by summation of dynamic data between 0 and 90 min after injection of ${ }^{18}$ F-FDG and were overlaid on the MRI template. ${ }^{*} p<0.05$

increased cortical or hippocampal markers of inflammation in high-fat fed, obese mice [64-66]; others report modest region-specific effects or no detectable effect on the hippocampus $[67,68]$. These differences may reflect differences in the severity of metabolic symptoms between mouse strains, diet composition (e.g., cholesterol and caloric and macronutrient content), and duration of treatment exposure. However, this may not be detectable by PET due to methodological issues.

In the current study, obesity induced some limitations including not only logistical and image quality issues due to scatter and attenuation but also in validation of analysis models where large differences in body weight affect radioligand distribution throughout the body. SUV has been widely validated as an outcome measure for ${ }^{18}$ F-FDG uptake adjusting for differences in body weight.
However, hyperglycemia is associated with reduced cerebral ${ }^{18}$ F-FDG uptake due to increased competition to cross the blood-brain barrier, likely resulting in an underestimation of cerebral metabolism in obese groups [69-71]. In the case of ${ }^{11} \mathrm{C}-\mathrm{PBR}-28$, systemic inflammation and increased TSPO binding in peripheral tissues of obese animals [72] may also have significant impacts on brain uptake. These factors are likely contributors to the reduction in in vivo brain ${ }^{11} \mathrm{C}-\mathrm{PBR}-28$ signals observed in obese mice; however, good agreement was observed between in vivo TSPO signals and immunoreactivity, validating the \%ID/g for quantifying TSPO in living brains.

\section{Conclusions}

Obesity combined with $A \beta$ infusion was found to increase both TSPO-PET signals and cerebral glucose 


\section{a}

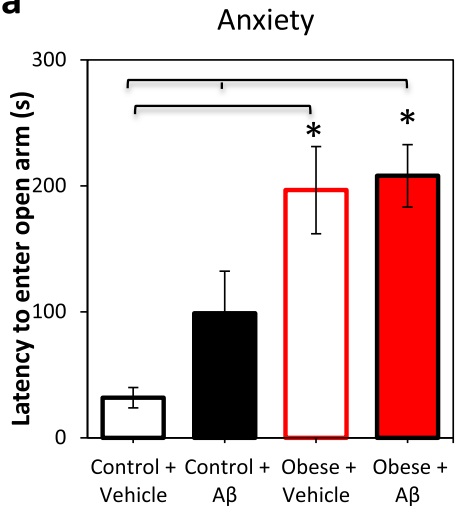

C

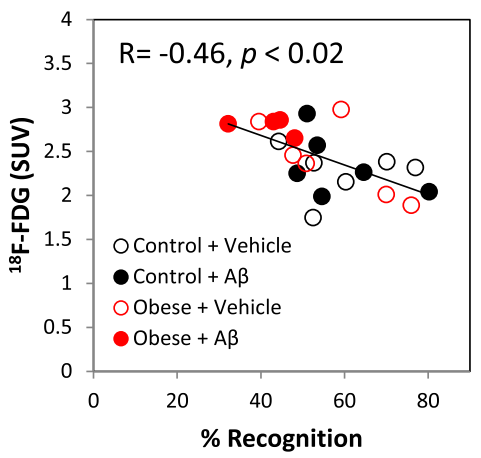

b

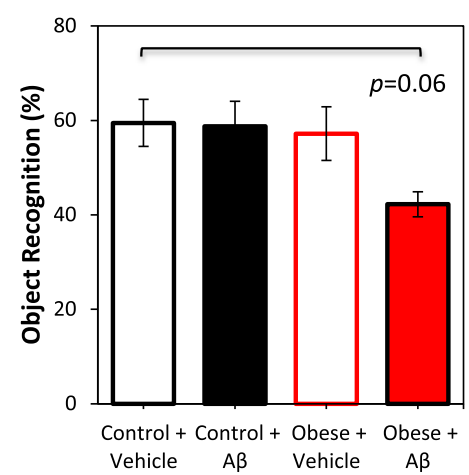

d

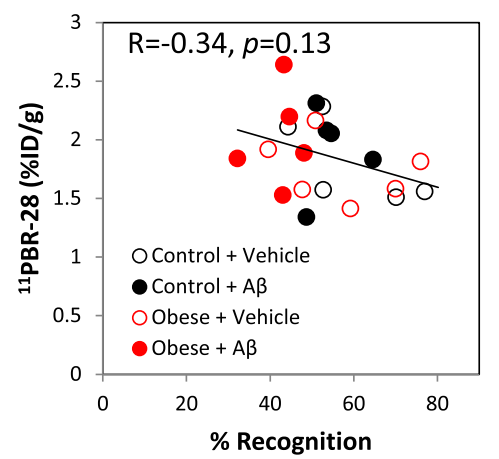

Fig. 7 Association between functional performance in anxiety and learning and memory tasks and ${ }^{18} \mathrm{~F}$-FDG and ${ }^{11} \mathrm{C}-\mathrm{PBR}-28 \mathrm{PET}$ signals. a A infusion and obesity increased anxiety-related behavior in the elevated plus maze. $\mathbf{b}$ A trend towards impaired learning and memory performance in A $\beta$-infused obese mice approached significance in the object recognition task. $\mathbf{c}$ Hippocampal ${ }^{18} \mathrm{~F}$-FDG signals significantly negatively correlated with learning and memory performance in the object recognition task. $\mathbf{d}$ No significant correlation between hippocampal ${ }^{11} \mathrm{C}-\mathrm{PBR}$ - 28 signals and learning and memory performance was observed, although both ${ }^{18} \mathrm{~F}-\mathrm{FDG}$ and ${ }^{11} \mathrm{C}-\mathrm{PBR}-28$ were significant predictors of learning and memory performance as assessed by multiple regression analysis. $p<0.05$

metabolism. These signals can predict learning and memory performance. In vivo TSPO signals were confirmed by ex vivo analyses and correlated with inflammatory markers of hippocampal gliosis and serum levels of cytokine and chemokines. In contrast, since hypermetabolic regions did not directly correspond to regions of increased TSPO signals, it may reflect early pathogenic effects of $A \beta$ toxicity on neurons rather than inflammation. These findings demonstrate the potential usefulness of TSPO and cerebral glucose metabolism for the investigation of interactions between midlife lifestyle factors and $\mathrm{A} \beta$ amyloidosis with the aid of neuroimaging.

\section{Acknowledgements}

The authors thank M. Ono, T. Minamihisamatsu, S. Sasaki and S. Uchida for technical support and assistance (National Institute of Radiological Sciences, NIRS), A. S. J. Wyatt for assistance with statistical analyses (University of Tokyo), and S. Chie for critical feedback on the manuscript (NIRS).

\section{Funding}

This work is supported by grants from Grants-in-Aid for Core Research for Evolutional Science and Technology (14533254), the Brain Mapping by
Integrated Neurotechnologies for Disease Studies (Brain/MINDS; 15653129), the Research and Development Grants for Dementia (16768966) to M. H. from the Japan Agency for Medical Research and Development, and the Japan Advanced Molecular Imaging Program and Scientific Research on Innovative Areas ("Brain Environment" 23111009 to M. H.) from the Ministry of Education, Culture, Sports, Science and Technology, Japan.

Availability of data and materials

There are no data, software, databases, or application/tool apart from that reported in the study. Data supporting the conclusions are presented in the current manuscript.

\section{Authors' contributions}

Experiments were designed and conceived by $\mathrm{AMB}, \mathrm{MT}$, and $\mathrm{MH}$. Data was collected by AMB, MT, MRZ, and BJ. Data was interpreted by all authors. The manuscript was written by $\mathrm{AMB}, \mathrm{ST}$, and $\mathrm{MH}$, and all authors read and approved the final manuscript.

\section{Competing interests}

The authors declare that they have no competing interests.

\section{Consent for publication \\ Not applicable.}

\section{Ethics approval and consent to participate}

All experimentation was carried out in strict accordance with the recommendations in the Guide for the Care and Use of Laboratory Animals 
of the National Institutes of Health and was approved by the Institutional Animal Care and Use Committee of the National Institutes for Quantum and Radiological Science and Technology, Japan. Consent to participate is not applicable.

\section{Author details}

'Department of Functional Brain Imaging Research, National Institutes for Quantum and Radiological Science and Technology, 4-9-1 Anagawa, Inage-ku, Chiba-shi, Chiba 263-8555, Japan. ²Department of Radiopharmaceutics Development, National Institutes for Quantum and Radiological Science and Technology, 4-9-1 Anagawa, Inage-ku, Chiba-shi, Chiba 263-8555, Japan. ${ }^{3}$ Neurobiology of Aging and Disease Laboratory, Lee Kong Chian School of Medicine, Nanyang Technological University, 59 Nanyang Drive, Singapore 636921, Singapore.

Received: 8 June 2016 Accepted: 20 August 2016

Published online: 31 August 2016

\section{References}

1. Organization WH: Obesity: preventing and managing the global epidemic. In WHO Technical Report Series. 2000; p. 252.

2. Xu WL, Atti AR, Gatz M, Pedersen NL, Johansson B, Fratiglioni L. Midlife overweight and obesity increase late-life dementia risk: a population-based twin study. Neurology. 2011;76:1568.

3. Loef M, Walach H. Midlife obesity and dementia: meta-analysis and adjusted forecast of dementia prevalence in the United States and China. Obesity. 2013;21:E51

4. Smith E, Hay P, Campbell L, Trollor JN. A review of the association between obesity and cognitive function across the lifespan: implications for nove approaches to prevention and treatment. Obesity Rev. 2011;12:740.

5. Thal DR, Rub U, Orantes M, Braak H. Phases of A beta-deposition in the human brain and its relevance for the development of AD. Neurology. 2002; 58:1791.

6. Ritchie K, Ritchie CW, Yaffe K, Skoog I, Scarmeas N. Is late-onset Alzheimer's disease really a disease of midlife? Alzheimers Dement. 2015;1:122

7. Mattson MP. Pathways towards and away from Alzheimer's disease. Nature. 2004;430:631.

8. Weiner MW, Veitch DP, Aisen PS, Beckett LA, Cairns NJ, Green RC, Harvey D, Jack CR, Jagust W, Liu E, et al. The Alzheimer's Disease Neuroimaging Initiative: a review of papers published since its inception. Alzheimers Dement. 2012;8:S1.

9. Ho L, Qin W, Pompl PN, Xiang Z, Wang J, Zhao Z, Peng Y, Cambareri G, Rocher A, Mobbs CV, et al. Diet-induced insulin resistance promotes amyloidosis in a transgenic mouse model of Alzheimer's disease. FASEB J. 2004. doi:10.1096/fj.03-0978fje.

10. Julien C, Tremblay C, Phivilay A, Berthiaume L, Émond V, Julien P, Calon F. High-fat diet aggravates amyloid-beta and tau pathologies in the $3 \times \mathrm{Tg}-\mathrm{AD}$ mouse model. Neurobiol Aging. 2010;31:1516.

11. Li L, Cao D, Garber DW, Kim H, Fukuchi K-I. Association of aortic atherosclerosis with cerebral $\beta$-amyloidosis and learning deficits in a mouse model of Alzheimer's disease. Am J Pathol. 2003;163:2155.

12. Levin-Allerhand JA, Lominska CE, Smith JD. Increased amyloid- $\beta$ levels in APPSWE transgenic mice treated chronically with a physiological high-fat high-cholesterol diet. J Nutr Health Aging. 2002;6:315.

13. Barron AM, Rosario ER, Elteriefi R, Pike CJ. Sex-specific effects of high fat diet on indices of metabolic syndrome in 3xTg-AD mice: implications for Alzheimer's disease. PLoS One. 2013;8:e78554.

14. Heppner FL, Ransohoff RM, Becher B. Immune attack: the role of inflammation in Alzheimer disease. Nat Rev Neurosci. 2015;16:358.

15. Heneka MT, Carson MJ, El Khoury J, Landreth GE, Brosseron F, Feinstein DL Jacobs AH, Wyss-Coray T, Vitorica J, Ransohoff RM, et al. Neuroinflammation in Alzheimer's disease. Lancet Neurol. 2015;14:388.

16. Yoshiyama Y, Hiquchi M, Zhang B, Huang SM, Iwata N, Saido TC, Maeda J, Suhara T, Trojanowski JQ, Lee VM. Synapse loss and microglial activation precede tangles in a P301S tauopathy mouse model. Neuron. 2007:53:337.

17. Ji B, Maeda J, Sawada M, Ono M, Okauchi T, Inaji M, Zhang M-R, Suzuki K, Ando K, Staufenbiel M, et al. Imaging of peripheral benzodiazepine receptor expression as biomarkers of detrimental versus beneficial glial responses in mouse models of Alzheimer's and other CNS pathologies. J Neurosci. 2008;28:12255.
18. Briard E, Zoghbi SS, Imaizumi M, Gourley JP, Shetty HU, Hong J, Cropley V, Fujita M, Innis RB, Pike WW. Synthesis and evaluation in monkey of two sensitive ${ }^{11} \mathrm{C}$-labeled aryloxyanilide ligands for imaging brain peripheral benzodiazepine receptors in vivo. J Med Chem. 2008:51:17.

19. Kreisl W, Lyoo CH, Wei M, Snow J, Jenko K, Morse C, Zoghbi S, Pike V, Turner R, Innis R. Serial imaging with [11C]PBR28 suggests increased neuroinflammation during the progression of Alzheimer's disease. Neurology. 2015;84:6.

20. Park E, Gallezot J-D, Delgadillo A, Liu S, Planeta B, Lin S-F, O'Connor K, Lim K, Lee J-Y, Chastre A, et al. 11C-PBR28 imaging in multiple sclerosis patients and healthy controls: test-retest reproducibility and focal visualization of active white matter areas. Eur J Nucl Med Mol Imaging. 2015;42:1081.

21. Walker MD, Dinelle K, Kornelsen R, Lee NV, Miao Q, Adam M, Takhar C, Mak E, Schulzer M, Farrer MJ, Sossi V. [11C]PBR28 PET imaging is sensitive to neuroinflammation in the aged rat. J Cereb Blood Flow Metab. 2015:35:1331

22. Imaizumi M, Kim HJ, Zoghbi SS, Briard E, Hong J, Musachio JL, Ruetzler C, Chuang DM, Pike WW, Innis RB, Fujita M. PET imaging with [11C]PBR28 can localize and quantify upregulated peripheral benzodiazepine receptors associated with cerebral ischemia in rat. Neurosci Lett. 2007:411:200.

23. Rocher AB, Chapon F, Blaizot X, Baron JC, Chavoix C. Resting-state brain glucose utilization as measured by $P E T$ is directly related to regional synaptophysin levels: a study in baboons. Neurolmage. 2003;20:1894.

24. Benzinger TL, Blazey T, Jack Jr CR, Koeppe RA, Su Y, Xiong C, Raichle ME, Snyder AZ, Ances BM, Bateman RJ, et al. Regional variability of imaging biomarkers in autosomal dominant Alzheimer's disease. PNAS. 2013;110:E4502.

25. Oh H, Habeck C, Madison C, Jagust W. Covarying alterations in $A \beta$ deposition, glucose metabolism, and gray matter volume in cognitively normal elderly. Human Brain Map. 2014;35:297.

26. Ashraf A, Fan Z, Brooks DJ, Edison P. Cortical hypermetabolism in MCI subjects: a compensatory mechanism? Eur J Nucl Med Mol Imaging. 2015; 42:447

27. Cohen AD, Price JC, Weissfeld LA, James J, Rosario BL, Bi W, Nebes RD, Saxton JA, Snitz BE, Aizenstein HA, et al. Basal cerebral metabolism may modulate the cognitive effects of $A \beta$ in mild cognitive impairment: an example of brain reserve. J Neurosci. 2009;29:14770.

28. Sancheti $H$, Patil I, Kanamori K, Diaz Brinton R, Zhang W, Lin A-L, Cadenas E. Hypermetabolic state in the 7-month-old triple transgenic mouse model of Alzheimer's disease and the effect of lipoic acid: a 13C-NMR study. J Cereb Blood Flow Metab. 2014;34:1749.

29. Luo F, Rustay NR, Ebert U, Hradil VP, Cole TB, Llano DA, Mudd SR, Zhang Y, Fox GB, Day M. Characterization of 7- and 19-month-old Tg2576 mice using multimodal in vivo imaging: limitations as a translatable model of Alzheimer's disease. Neurobiol Aging. 2012;33:933.

30. Rojas S, Herance JR, Gispert JD, Abad S, Torrent E, Jimenez X, Pareto D, Perpina U, Sarroca S, Rodriguez E, et al. In vivo evaluation of amyloid deposition and brain glucose metabolism of 5XFAD mice using positron emission tomography. Neurobiol Aging. 2013:34:1790.

31. Poisnel G, Herard AS, El Tannir El Tayara N, Bourrin E, Volk A, Kober F, Delatour B, Delzescaux T, Debeir T, Rooney T, et al. Increased regional cerebral glucose uptake in an APP/PS1 model of Alzheimer's disease. Neurobiol Aging. 2012;33:1995.

32. Craft JM, Watterson DM, Frautschy SA, Van Eldik LJ. Aminopyridazines inhibit beta-amyloid-induced glial activation and neuronal damage in vivo. Neurobiol Aging. 2004;25:1283.

33. Wang M, Yoder KK, Gao M, Mock BH, Xu XM, Saykin AJ, Hutchins GD, Zheng $\mathrm{QH}$. Fully automated synthesis and initial PET evaluation of [11C]PBR28. Bioorg Med Chem Lett. 2009;19:5636.

34. Maeda J, Zhang MR, Okauchi T, Ji B, Ono M, Hattori S, Kumata K, Iwata N, Saido TC, Trojanowski JQ, et al. In vivo positron emission tomographic imaging of glial responses to amyloid-beta and tau pathologies in mouse models of Alzheimer's disease and related disorders. J Neurosci. 2011;31:4720.

35. James ML, Belichenko NP, Nguyen TV, Andrews LE, Ding Z, Liu H, Bodapati D, Arksey N, Shen B, Cheng Z, et al. PET imaging of translocator protein $(18 \mathrm{kDa})$ in a mouse model of Alzheimer's disease using N-(2,5-dimethoxybenzyl)-2-18 F-fluoro-N-(2-phenoxyphenyl) acetamide. J Nucl Med. 2015:56:311.

36. Venneti S, Lopresti BJ, Wang G, Hamilton RL, Mathis CA, Klunk WE, Apte UM Wiley CA. PK11195 labels activated microglia in Alzheimer's disease and in vivo in a mouse model using PET. Neurobiol Aging. 2009;30:1217.

37. Maeda J, Ji B, Irie T, Tomiyama T, Maruyama M, Okauchi T, Staufenbiel M, Iwata N, Ono M, Saido TC, et al. Longitudinal, quantitative assessment of 
amyloid, neuroinflammation, and anti-amyloid treatment in a living mouse model of Alzheimer's disease enabled by positron emission tomography. J Neurosci. 2007;27:10957.

38. Meissburger B, Stachorski L, Roder E, Rudofsky G, Wolfrum C. Tissue inhibitor of matrix metalloproteinase 1 (TIMP1) controls adipogenesis in obesity in mice and in humans. Diabetologia. 2011;54:1468.

39. Neels JG, Badeanlou L, Hester KD, Samad F. Keratinocyte-derived chemokine in obesity: expression, regulation, and role in adipose macrophage infiltration and glucose homeostasis. J Biol Chem. 2009;284:20692.

40. Nunemaker CS, Chung HG, Verrilli GM, Corbin KL, Upadhye A, Sharma PR. Increased serum CXCL1 and CXCL5 are linked to obesity, hyperglycemia, and impaired islet function. J Endocrinol. 2014;222:267.

41. Rouault C, Pellegrinelli V, Schilch R, Cotillard A, Poitou C, Tordjman J, Sell H, Clement K, Lacasa D. Roles of chemokine ligand-2 (CXCL2) and neutrophils in influencing endothelial cell function and inflammation of human adipose tissue. Endocrinol. 2013;154:1069.

42. Kim D, Kim J, Yoon JH, Ghim J, Yea K, Song P, Park S, Lee A, Hong CP, Jang MS, et al. CXCL12 secreted from adipose tissue recruits macrophages and induces insulin resistance in mice. Diabetologia. 2014;57:1456.

43. Huber J, Kiefer F, Zeyda M, Ludvik B, Silberhumer G, Prager G, Stulnig TM. CCL2 and CCL3 chemokine gene expression and their receptors in human visceral and subcutaneous adipose tissue is associated with obesity and insulin resistance. Exp Clin Endocrinol Diabetes. 2007;115:3215.

44. Keophiphath M, Rouault C, Divoux A, Clement K, Lacasa D. CCL5 promotes macrophage recruitment and survival in human adipose tissue. Arterioscler Thromb Vasc Biol. 2010;30:39.

45. Doi Y, Takeuchi H, Mizoguchi H, Fukumoto K, Horiuchi H, Jin S, Kawanokuchi J, Parajuli B, Sonobe Y, Mizuno T, Suzumura A. Granulocyte-colony stimulating factor attenuates oligomeric amyloid beta neurotoxicity by activation of neprilysin. PLoS One. 2014;9:e103458.

46. Tsai K-J, Tsai Y-C, Shen C-KJ. G-CSF rescues the memory impairment of animal models of Alzheimer's disease. J Experimental Med. 2007;204:1273.

47. Kim JY, Kim DH, Kim JH, Lee D, Jeon HB, Kwon SJ, Kim SM, Yoo YJ, Lee EH, Choi SJ, et al. Soluble intracellular adhesion molecule-1 secreted by human umbilical cord blood-derived mesenchymal stem cell reduces amyloid-beta plaques. Cell Death Differ. 2012;19:680.

48. Wang Q, Xu Y, Chen JC, Qin YY, Liu M, Liu Y, Xie MJ, Yu ZY, Zhu Z, Wang W. Stromal cell-derived factor 1alpha decreases beta-amyloid deposition in Alzheimer's disease mouse model. Brain Res. 2012;1459:15.

49. Craft JM, Watterson DM, Hirsch E, Van Eldik LJ. Interleukin 1 receptor antagonist knockout mice show enhanced microglial activation and neuronal damage induced by intracerebroventricular infusion of human beta-amyloid. J Neuroinflammation. 2005;2:15

50. Vlassenko AG, Vaishnavi SN, Couture L, Sacco D, Shannon BJ, Mach RH, Morris JC, Raichle ME, Mintun MA. Spatial correlation between brain aerobic glycolysis and amyloid- $\beta$ (Aß) deposition. PNAS. 2010;107:17763.

51. Kuchibhotla KV, Lattarulo CR, Hyman BT, Bacskai BJ. Synchronous hyperactivity and intercellular calcium waves in astrocytes in Alzheimer mice. Science. 2009:323:1211

52. Busche MA, Eichhoff $G$, Adelsberger $H$, Abramowski D, Wiederhold K-H, Haass C, Staufenbiel M, Konnerth A, Garaschuk O. Clusters of hyperactive neurons near amyloid plaques in a mouse model of Alzheimer's disease. Science. 2008;321:1686.

53. Busche MA, Chen X, Henning HA, Reichwald J, Staufenbiel M, Sakmann B, Konnerth A. Critical role of soluble amyloid- $\beta$ for early hippocampal hyperactivity in a mouse model of Alzheimer's disease. PNAS. 2012;109:8740.

54. Palop JJ, Chin J, Roberson ED, Wang J, Thwin MT, Bien-Ly N, Yoo J, Ho KO, Yu GQ, Kreitzer A, et al. Aberrant excitatory neuronal activity and compensatory remodeling of inhibitory hippocampal circuits in mouse models of Alzheimer's disease. Neuron. 2007;55:697.

55. Sperling RA, LaViolette PS, O'Keefe K, O'Brien J, Rentz DM, Pihlajamaki M, Marshall G, Hyman BT, Selkoe DJ, Hedden T, et al. Amyloid deposition is associated with impaired default network function in older persons without dementia. Neuron. 2009:63:178

56. Dickerson BC, Salat DH, Greve DN, Chua EF, Rand-Giovannetti E, Rentz DM, Bertram L, Mullin K, Tanzi RE, Blacker D, et al. Increased hippocampa activation in mild cognitive impairment compared to normal aging and $A D$. Neurology. 2005;65:404.

57. Celone KA, Calhoun VD, Dickerson BC, Atri A, Chua EF, Miller SL, DePeau K, Rentz DM, Selkoe DJ, Blacker D, et al. Alterations in memory networks in mild cognitive impairment and Alzheimer's disease: an independent component analysis. J Neurosci. 2006;26:10222.

58. Kircher T, Weis S, Freymann K, Erb M, Jessen F, Grodd W, Heun R, Leube DT. Hippocampal activation in patients with mild cognitive impairment is necessary for successful memory encoding. JNNP. 2007;78:812.

59. Miller SL, Fenstermacher E, Bates J, Blacker D, Sperling RA, Dickerson BC. Hippocampal activation in adults with mild cognitive impairment predicts subsequent cognitive decline. JNNP. 2008;79:630.

60. Yassa MA, Stark SM, Bakker A, Albert MS, Gallagher M, Stark CE. High-resolution structural and functional MRI of hippocampal CA3 and dentate gyrus in patients with amnestic mild cognitive impairment. Neurolmage. 2010;51:1242.

61. Bondi MW, Houston WS, Eyler LT, Brown GG. fMRI evidence of compensatory mechanisms in older adults at genetic risk for Alzheimer disease. Neurology. 2005;64:501.

62. Bookheimer SY, Strojwas MH, Cohen MS, Saunders AM, Pericak-Vance MA, Mazziotta JC, Small GW. Patterns of brain activation in people at risk for Alzheimer's disease. NEJM. 2000;343:450.

63. Bassett SS, Yousem DM, Cristinzio C, Kusevic I, Yassa MA, Caffo BS, Zeger SL. Familial risk for Alzheimer's disease alters fMRI activation patterns. Brain. 2006;129:1229.

64. Koga S, Kojima A, Kuwabara S, Yoshiyama Y. Immunohistochemical analysis of tau phosphorylation and astroglial activation with enhanced leptin receptor expression in diet-induced obesity mouse hippocampus. Neurosci Lett. 2014:571:11

65. Jayaraman A, Lent-Schochet D, Pike CJ. Diet-induced obesity and low testosterone increase neuroinflammation and impair neural function. J Neuroinflam. 2014;11:162.

66. Puig KL, Floden AM, Adhikari R, Golovko MY, Combs CK. Amyloid precursor protein and proinflammatory changes are regulated in brain and adipose tissue in a murine model of high fat diet-induced obesity. PLoS One. 2012;7:e30378.

67. Zhang L, Dasuri K, Fernandez-Kim S-O, Bruce-Keller AJ, Freeman LR, Pepping JK, Beckett TL, Murphy MP, Keller JN. Prolonged diet induced obesity has minimal effects towards brain pathology in mouse model of cerebral amyloid angiopathy: Implications for studying obesity-brain interactions in mice. BBA-Mol Basis Dis. 2013;1832:1456.

68. Buckman LB, Thompson MM, Moreno HN, Ellacott KL. Regional astrogliosis in the mouse hypothalamus in response to obesity. J Comp Neurol. 2013; 521:1322.

69. Ishizu K, Nishizawa S, Yonekura Y, Sadato N, Magata Y, Tamaki N, Tsuchida T, Okazawa H, Miyatake S, Ishikawa M, et al. Effects of hyperglycemia on FDG uptake in human brain and glioma. J Nucl Med. 1994;35:1104.

70. Yamada K, Endo S, Fukuda H, Abe Y, Yoshioka S, Itoh M, Kubota K, Hatazawa J, Satoh T, Matsuzawa T, et al. Experimental studies on myocardial glucose metabolism of rats with 18 F-2-fluoro-2-deoxy-D-glucose. Eur J Nucl Med. 1985;10:341

71. Wahl RL, Henry CA, Ethier SP. Serum glucose: effects on tumor and normal tissue accumulation of 2-[F-18]-fluoro-2-deoxy-D-glucose in rodents with mammary carcinoma. Radiology. 1992;183:643.

72. Giannaccini G, Betti L, Palego L, Pirone A, Schmid L, Lanza M, Fabbrini L, Pelosini C, Maffei M, Santini F, et al. Serotonin transporter (SERT) and translocator protein (TSPO) expression in the obese ob/ob mouse. BMC Neurosci. 2011;12:18

\section{Submit your next manuscript to BioMed Central and we will help you at every step:}

- We accept pre-submission inquiries

- Our selector tool helps you to find the most relevant journal

- We provide round the clock customer support

- Convenient online submission

- Thorough peer review

- Inclusion in PubMed and all major indexing services

- Maximum visibility for your research

Submit your manuscript at www.biomedcentral.com/submit 